\title{
Vulvodynia Treated with Acupuncture or Electromyographic Biofeedlback
}

\author{
Oroma B. Nwanodi*, Melanie M. Tidman \\ Department of Interdisciplinary Health Studies, A. T. Still University Arizona School of Health Sciences, Mesa, \\ USA \\ Email: ${ }^{*}$ o.nwanodi@juno.com
}

Received 5 March 2014; revised 11 April 2014; accepted 28 April 2014

Copyright (C) 2014 by authors and Scientific Research Publishing Inc.

This work is licensed under the Creative Commons Attribution International License (CC BY). http://creativecommons.org/licenses/by/4.0/

(c) (i) Open Access

\section{Abstract}

First, second, and third line medical treatments of vulvodynia are of limited efficacy. Surgical resection, the fourth line treatment of vulvodynia, may have unforgiving sequela. Therefore, acupuncture and electromyographic (EMG) biofeedback could bridge between medical and surgical treatments of vulvodynia. Of note, EMG biofeedback is more frequently recommended in treatment algorithms for vulvodynia than is acupuncture. Trials of acupuncture for unprovoked vulvodynia demonstrate variable efficacy, whereas trials of EMG biofeedback for provoked vulvodynia demonstrate consistent efficacy. Trials of acupuncture for treatment of provoked and unprovoked vulvodynia using identical acupoints, a vulvar algesiometer for objective pain measurement, and standardized, validated, tools for outcome assessment are needed. Such trials may enable comparison of acupuncture to EMG biofeedback for the treatment of provoked and unprovoked vulvodynia. Similarly, trials of EMG biofeedback for treatment of unprovoked vulvodynia would increase the knowledge base of EMG biofeedback for treatment of vulvodynia.

\section{Keywords}

Acupuncture, Biofeedback, Electromyography, Vestibulodynia, Vulvodynia

\section{Introduction}

This article is a clinical review article on vulvodynia for health care providers including physical therapists, with an interest in alternative, complementary, holistic, or integrated medicine. As the target audience's knowledge base may not focus on gynecology, following the introductory section the relevant anatomy will be reviewed.

The purpose of this review article is to determine whether acupuncture and electromyography (EMG) bio-

${ }^{*}$ Corresponding author. 
feedback have comparable efficacy in the treatment of vulvodynia or vestibulodynia. A secondary goal is to identify why the American guideline for treatment of vulvodynia does not support usage of acupuncture whereas the British guideline supports usage of acupuncture. Additionally, future study options for the treatment of vulvodynia with acupuncture that may use a vulvar algesiometer will be identified. To this end, the pathophysiology, classification, evaluation, and treatments of vulvodynia will be reviewed. Such review should clarify the pathophysiologic basis of vulvodynia, which contributes to the biologic plausibility of both acupuncture and EMG biofeedback for treatment of vulvodynia. Second, the efficacy of acupuncture for treatment of vulvodynia will be presented. Third, the efficacy of EMG biofeedback for treatment of vulvodynia will be reviewed. Fourth, an attempt will be made to determine the comparative treatment efficacy of these two treatment modalities. Such elucidation of comparative efficacy or lack thereof, between acupuncture and EMG biofeedback may reconcile the different recommendations for the treatment of vulvodynia in the American and British guidelines.

\subsection{Definition of Terminology}

Vulvodynia, a chronic, disabling, burning, discomfort of the vulva was first described in 1976, and given distinction as a discrete clinical entity by the International Society for the Study of Vulval Disease (ISSVD) in 1985 [1]. Initially, vulval vestibulitis was regarded as a distinct disorder from vulvodynia. However, in 2005 the ISSVD reclassified vulval vestibulitis as vestibulodynia, a localized vulvodynia [2].

\subsection{Prevalence and Comorbidities}

Provoked vestibulodynia has a prevalence of $12 \%$ of women [3]. Vestibulodynia is found in $15 \%$ of gynecology patients [4]. Immunologic, infectious, inflammatory, neoplastic, and neurologic pathologies should be excluded prior to making a diagnosis of vulvodynia [1] [2] [5]. Anxiety, depression, interstitial cystitis, irritable bowel syndrome, and sexual dysfunction are co-morbidities of vulva pain syndromes [1] [3] [6]. Provoked vestibulodynia is significantly associated with chronic fatigue syndrome (odds ratio $[\mathrm{OR}]=2.78$ ), depression $(\mathrm{OR}=2.99)$, fibromyalgia $(\mathrm{OR}=2.15)$, irritable bowel syndrome $(\mathrm{OR}=1.86)$, urinary tract infections $(\mathrm{OR}=6.15)$, and yeast infections $(\mathrm{OR}=4.24)$ [3]. Vulvodynia is known to impair partner intimacy [1] [7], presumably via contribution to the development of dyspareunia [8], hypoactive sexual desire, orgasmic dysfunction, and vaginismus [6].

\section{Methods}

The PubMed database was searched on August 31, 2013, with the terms "acupuncture treatment vulvodynia", "electromyographic biofeedback vulvodynia", "acupuncture treatment vulvar vestibulitis", and "electromyographic biofeedback vulvar vestibulitis", yielding 10 English language articles. Eight articles were found from the reference lists of the first 10 articles. Three references were sought as original sources of standardized testing instruments. Two references were taken from prior work for neurological background, and one reference for anatomy (Figure 1). Of these, three studies on acupuncture and four studies on EMG biofeedback will be reviewed (Table 1).

\section{Anatomy, Pathophysiology, Classification, Evaluation, and Treatment of Vulvodynia}

\subsection{Anatomy}

The vulva is bounded cephalad by the mons pubis, bilaterally by the lateral margins of the labia majora, and caudad by the anus [9]. Within the vulva, the vestibule is demarcated bilaterally by the labia minora forming Hart's line, cephalad by the clitoris, caudad by the posterior fourchette and fossa navicularis, and in depth by the vaginal introitus [10] [11]. Being contained within the vulva, the vestibule may not be exposed to all the stimuli which the larger vulva is exposed to.

\subsection{Pathophysiology}

The vulva is primarily innervated by the pudendal nerve plexus from S3 and S4 [12]. Cephalad and lateral portions of the vulva derive innervation from the ilioinguinal, genitofemoral, and posterior femoral cutaneous nerves from L1, L1 and L2, and S1 to S3 respectively [13]. Vulvar pain may be transmitted via rapid, myelin 
Table 1. Description of studies included in the review.

\begin{tabular}{|c|c|c|c|c|c|c|c|c|}
\hline $\begin{array}{l}\text { Study/ } \\
\text { Year }\end{array}$ & Study Design & $\begin{array}{l}\text { Subject } \\
\text { Sources/ } \\
\text { Diagnosis }\end{array}$ & Treatment of Interest & $\begin{array}{l}\text { Treatment } \\
\text { Frequency }\end{array}$ & $\begin{array}{l}\text { Number of } \\
\text { Subjects }\end{array}$ & Outcome Measures & Follow-Up & Results \\
\hline $\begin{array}{l}\text { Reference } \\
{[17] / 2001}\end{array}$ & $\begin{array}{l}\text { Quasi- } \\
\text { experimental. } \\
\text { No blinding, } \\
\text { control } \\
\text { group(s), or } \\
\text { randomization }\end{array}$ & $\begin{array}{l}\text { Adolescent } \\
\text { health center/ } \\
\text { vestibulitis }\end{array}$ & $\begin{array}{c}\text { Acupuncture } \\
4 \text { local and } 2 \text { distal points } \\
\text { were always used, an } \\
\text { additional } 2-5 \text { points } \\
\text { couldalso be used }\end{array}$ & $\begin{array}{l}\text { Once or } \\
\text { twice } \\
\text { weekly for } \\
10 \text { treat- } \\
\text { ments in } \\
\text { total }\end{array}$ & $\begin{array}{l}14 \text { women } \\
\text { aged } 19-26 \\
\text { years; } 13 \\
\text { completed } \\
\text { treatment }\end{array}$ & $\begin{array}{l}\text { VAS pain score of } \\
0-10, \text { negative/positive } \\
\text { QOL questionnaire }\end{array}$ & $\begin{array}{l}11 \text { subjects } \\
\text { at } 3 \\
\text { months } \\
\text { after last } \\
\text { treatment } \\
\text { session }\end{array}$ & $\begin{array}{c}\text { Statistically significant } \\
\text { changes to negative and } \\
\text { positive QOL factors } \\
\mathrm{p}=0.01 \text { and } \mathrm{p}=0.001\end{array}$ \\
\hline $\begin{array}{l}\text { Reference } \\
{[12] / 1995}\end{array}$ & $\begin{array}{l}\text { Quasi- } \\
\text { experimental } \\
\text { No blinding, } \\
\text { control } \\
\text { group(s), or } \\
\text { randomization }\end{array}$ & $\begin{array}{l}\text { Vulval } \\
\text { clinic/vulvar } \\
\text { vestibulitis }\end{array}$ & $\begin{array}{l}\text { EMG biofeedback } \\
\text { In-home pelvic floor } \\
\text { muscle exercises with } \\
\text { vaginal sensor, portable } \\
\text { EMG biofeedback } \\
\text { instrument, computerized } \\
\text { EMG data acquisition }\end{array}$ & $\begin{array}{l}\text { Twice daily } \\
\text { for an } \\
\text { average of } \\
16 \text { weeks }\end{array}$ & $\begin{array}{c}\text { 33women } \\
\text { aged } 21-45 \\
\text { years. Mean } \\
\text { age } 31.5 \\
\text { years. }\end{array}$ & $\begin{array}{l}\text { Subjective pain scale } \\
\text { of } 0-10, \text { frequency of } \\
\text { coitus, EMG amplitude } \\
\text { for contraction, } \\
\text { relaxation, and rest } \\
\text { periods }\end{array}$ & 6 months & $\begin{array}{c}\text { Decreased resting pelvic } \\
\text { muscle tension and } \\
\text { instability by } 68 \% \text { and } 62 \% \text {. } \\
\text { Decreased subjective pain by } \\
83 \% \text {. Coitus resumed by } \\
78 \% \text { of abstainers }\end{array}$ \\
\hline $\begin{array}{l}\text { Reference } \\
{[8] / 2001}\end{array}$ & $\begin{array}{c}\text { Block } \\
\text { randomization. } \\
\text { Non-blinded. } \\
\text { Control groups } \\
\text { of group cogni- } \\
\text { tive behavior } \\
\text { therapy, vesti- } \\
\text { bulectomy }\end{array}$ & $\begin{array}{l}\text { Media } \\
\text { advertisement } \\
\text { and referrals/ } \\
\text { dyspareunia } \\
\text { due to vulvar } \\
\text { vestibulitis }\end{array}$ & $\begin{array}{c}\text { EMG biofeedback } \\
\text { In-home pelvic floor } \\
\text { muscle exercises with } \\
\text { vaginal sensor, portable } \\
\text { EMG home trainer, } \\
\text { computerized EMG data } \\
\text { acquisition }\end{array}$ & $\begin{array}{l}\text { Twice daily } \\
\text { for } 12 \\
\text { weeks }\end{array}$ & $\begin{array}{l}29 \text { per group. } \\
\text { Mean age } \\
26.8 \text { years. } \\
\text { Total of } 9 \\
\text { subjects } \\
\text { overall } \\
\text { discontinued }\end{array}$ & $\begin{array}{l}\text { PRI and sensory scales } \\
\text { of the McGill Pain } \\
\text { Questionnaire, } \\
\text { frequency of coitus, } \\
\text { Derogatis Sexual } \\
\text { Functioning Inventory, } \\
\text { Brief Symptom } \\
\text { Inventory }\end{array}$ & 6 months & $\begin{array}{l}\text { Intention-to-treat analysis } \\
\text { statistically significant pain } \\
\text { reduction in each group, } \\
\text { greatest in vestibulectomy } \\
\text { group. }\end{array}$ \\
\hline $\begin{array}{l}\text { Reference } \\
{[22] / 2001}\end{array}$ & $\begin{array}{l}\text { Quasi- } \\
\text { experimental } \\
\text { No blinding, } \\
\text { control } \\
\text { group(s), or } \\
\text { randomization }\end{array}$ & $\begin{array}{l}\text { Clinic/vulvar } \\
\text { vestibulitis }\end{array}$ & $\begin{array}{l}\text { EMG biofeedback } \\
\text { In-home pelvic floor } \\
\text { muscle exercises with } \\
\text { vaginal sensor, portable } \\
\text { EMG home trainer, } \\
\text { computerized EMG } \\
\text { data acquisition }\end{array}$ & $\begin{array}{l}\text { Twice daily } \\
\text { for } 11 \\
\text { months }\end{array}$ & $\begin{array}{c}29 \text { women } \\
\text { aged } 25-48 \\
\text { years }\end{array}$ & $\begin{array}{l}\text { Subjective pain scale } \\
\text { of } 0 \text { - } 10 \text { for } \\
\text { assessment of } \\
\text { dyspareunia. EMG } \\
\text { amplitude for } \\
\text { contraction and } \\
\text { relaxation }\end{array}$ & None & $\begin{array}{l}\text { Significant decrease in pain } \\
\text { for } 84.7 \% \text { of subjects. Coitus } \\
\text { resumed by } 69 \% \text { of subjects }\end{array}$ \\
\hline $\begin{array}{l}\text { Reference } \\
{[23] / 2006}\end{array}$ & $\begin{array}{l}\text { Joint computer } \\
\text { generated } \\
\text { randomization, } \\
\text { control group } \\
\text { given } 2 \% \\
\text { topical } \\
\text { lidocaine gel } \\
\text { and } 5 \% \\
\text { lidocaine } \\
\text { ointment }\end{array}$ & $\begin{array}{l}\text { Two vulvar } \\
\text { clinics/vulvar } \\
\text { vestibulitis }\end{array}$ & $\begin{array}{l}\text { EMG biofeedback } \\
\text { In-home pelvic floor } \\
\text { muscle exercises with } \\
\text { vaginal sensor, portable } \\
\text { EMG home trainer, } \\
\text { computerized EMG } \\
\text { data acquisition }\end{array}$ & $\begin{array}{l}\text { Twice daily } \\
\text { for } 4 \text { months }\end{array}$ & $\begin{array}{l}23 \text { women } \\
\text { per group }\end{array}$ & $\begin{array}{c}\text { Negative/positive QOL } \\
\text { questionnaire, PRIME } \\
\text { MD, Short Form } 36, \\
\text { VAS } 0 \text { - } 100 \text { pain } \\
\text { scale, Vulvar pressure } \\
\text { pain threshold } \\
\text { measured by vulvar } \\
\text { algesiometer calibrated } \\
\text { for } 3 \text { - } 1000 \text { grams } \\
\text { force }\end{array}$ & $\begin{array}{l}6 \text { and } 12 \\
\text { months }\end{array}$ & $\begin{array}{l}\text { Equivalent improvement in } \\
\text { vestibular pressure pain } \\
\text { thresholds, QOL, and coitus } \\
\text { were achieved by each } \\
\text { treatment group. }\end{array}$ \\
\hline
\end{tabular}

EMG, Electromyography; FSFI, Female Sexual Function Index; PCS, Pain Catastrophizing Scale; PRI, Pain Rating Index; PVAQ, Pain Vigilance and Awareness Questionnaire; PRIME MD, Primary Care Evaluation of Mental Disorders; QOL, Quality of Life; VAS, Visual analogue scale.

ated, A- $\delta$ elta fibers with encephalin mediated spinal cord synapses between inhibitory communication cells and Waldeyer cells connected with the spinothalamic tract and serotonin mediated descending pain inhibitory channels [1]. An initial painful stimulus to the vulva can cause central pain sensitization.

In central pain sensitization the dorsal horn neurons are hypersensitized to any subsequent vulval stimulus [14]. Meaning that, after the initial provocation to the vulva, nociceptor thresholds are lowered and hyperalgesia occurs [7]. Now, progressively reduced stimuli can generate an increasingly greater pain response [7]. Distal- 


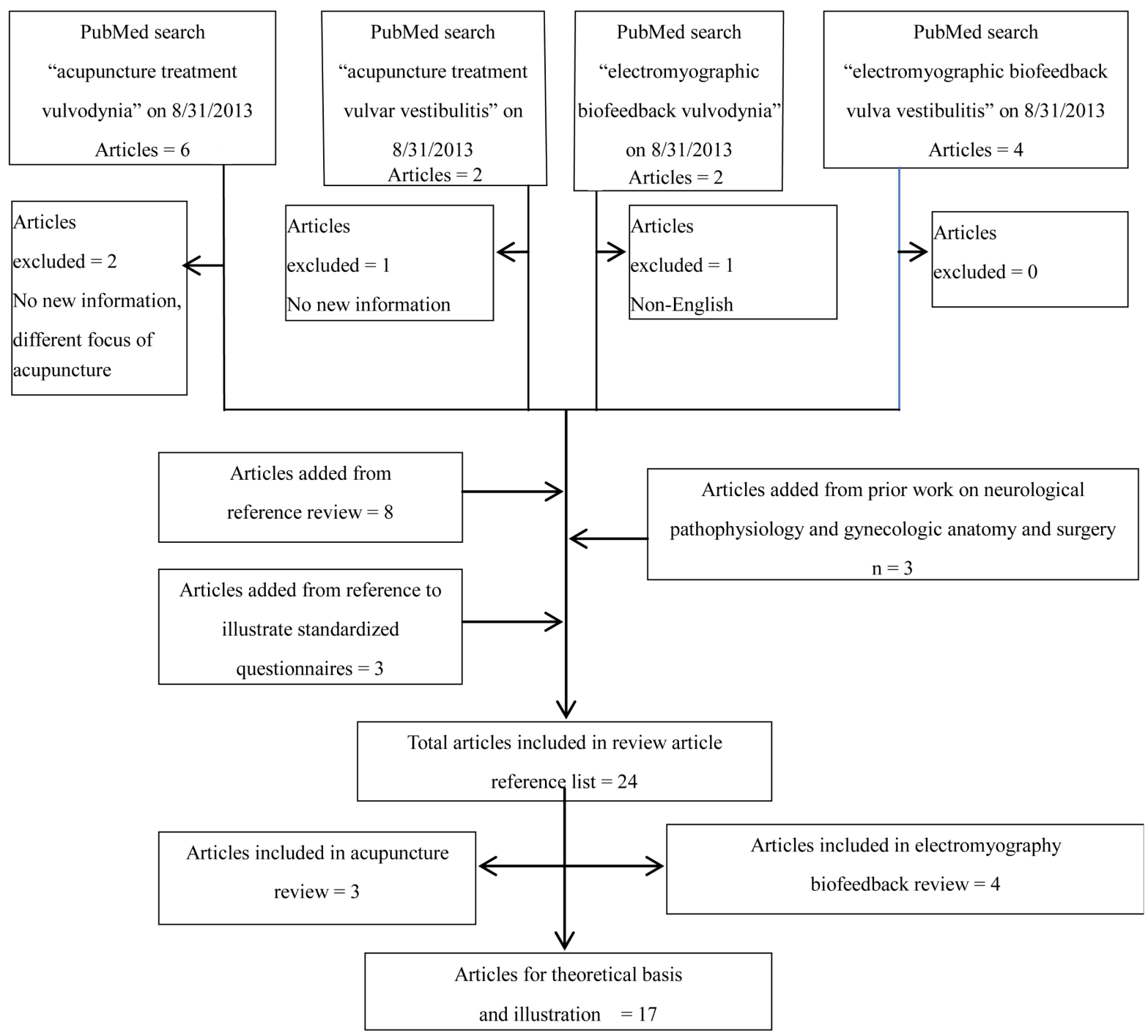

Figure 1. Article selection flow chart.

stimuli may elicit a response previously derived from local stimuli. The nociceptor field of reception increases with central sensitization and hyperalgesia [7]. Allodynia follows when nociceptors respond to what would ordinarily be non-noxious stimuli [7]. Persistent pelvic floor muscle stimulation may progress into contracture of the pubovaginalis and puborectalis portions of the pubococcygeus muscle [7] which receive innervation from S3 and S4 via the pudendal nerve [12]. Unprovoked myofascial pain ensues [7]. Baseline vulval electromyography (EMG) of healthy female controls averages $1-2 \mu \mathrm{V}$ RMS [12]. Women with provoked vulvodynia have baseline EMG of $2.5 \mu \mathrm{V}$ RMS, whereas women with unprovoked vulvodynia demonstrate further increased voltage of 3 - $5 \mu \mathrm{V}$ RMS [12]. The progressive increase in vulva EMG voltage from healthy controls with normal pain sensation may reflect disease progression from central sensitization with hyperalgesia in provoked vulvodynia, to allodynia in unprovoked vulvodynia.

Alternatively, the concept of cross-talk pain from visceral inflammation postulates that normally inactive mucosal afferents of the bladder, urethra, and vagina are activated when sympathetic nervous system synapses are shared with afferents from viscera including the distal large intestines and rectum [14]. The pudendal dorsal root ganglia of S2 through S4 are shared with parasympathetic pelvic splanchnic nerves innervating the vagina and cervix, the inferior hypogastric plexus (from which the pelvic nerves derives) innervating the uterus and cervix, sympathetic sacral splanchnic nerves, and the vagal nerve which innervates the vagina, cervix, and uterus. 
The ilioinguinal, genitofemoral, and posterior femoral cutaneous nerves share the inferior mesenteric ganglia with the lumbar splanchnic nerve from T12. In turn, the least splanchnic nerve from T12 shares the celiac and superior mesenteric ganglia with the greater and lesser splanchnic nerves. Therefore, innervation deriving from T12 can expose vulva innervation to stimuli from the ascending and transverse colon, kidney, liver, small and large intestines, spleen, stomach, and pancreas [15].

Up to $15 \%$ of afferents combine somatic and para-sympathetic motor activity permitting neurogenic sensitization, upregulation, and neurogenic inflammation in organs distant from the original inciting event, resulting in cross-talk pain [14] [16]. The anatomic location and etiologic pathophysiology of vulvodynia described above are important determinants of classification of vulvodynia and extent to which surgical treatment may eventually be recommended.

\subsection{Classification of Vulvodynia}

The ISSVD distinguishes between generalized vulvodynia of the entire vulva and localized vulvodynia pertaining to specific parts of the vulva [2]. Vestibulodynia is a localized vulvodynia of the vestibule anatomically described above [10] [11]. Generalized and localized vulvodynia may be provoked by nonsexual stimuli, sexual stimuli, or a combination thereof. Alternatively, generalized and localized vulvodynia may be unprovoked, or may result from a combination of provocation and non-provocation based on the described theories of central sensitization, allodynia, and cross-talk.

According to Friedrich's criteria, vestibulodynia involves six months of vestibular erythema, elicitation of pain upon application of pressure to the vestibulum, and extreme pain upon vulva penetration [17]. The classifications of provoked or unprovoked vulvodynia and vestibulodynia may affect treatment of refractory cases.

\subsection{Evaluation of Vulvodynia}

On physical exam, pain is elicited by the poorly reproducible operator dependent application of a cotton swab to the vulva [10] [11]. Therefore, a vulvar algesiometer (Figure 2) that measures pressure pain was developed [18]. Using four vulvar locations (Figure 3) for the vulvar algesiometer a correlation was found between 25 patients' subjective reports of pain and objective vulvar algesiometer scores. Post-treatment patients were able to tolerate increased force setting of the vulvar algesiometer force probe [18].

\subsection{Treatment of Vulvodynia}

Initially, vulvodynia and vestibulodynia are treated identically. Acute vulvodynia of less than three months du-

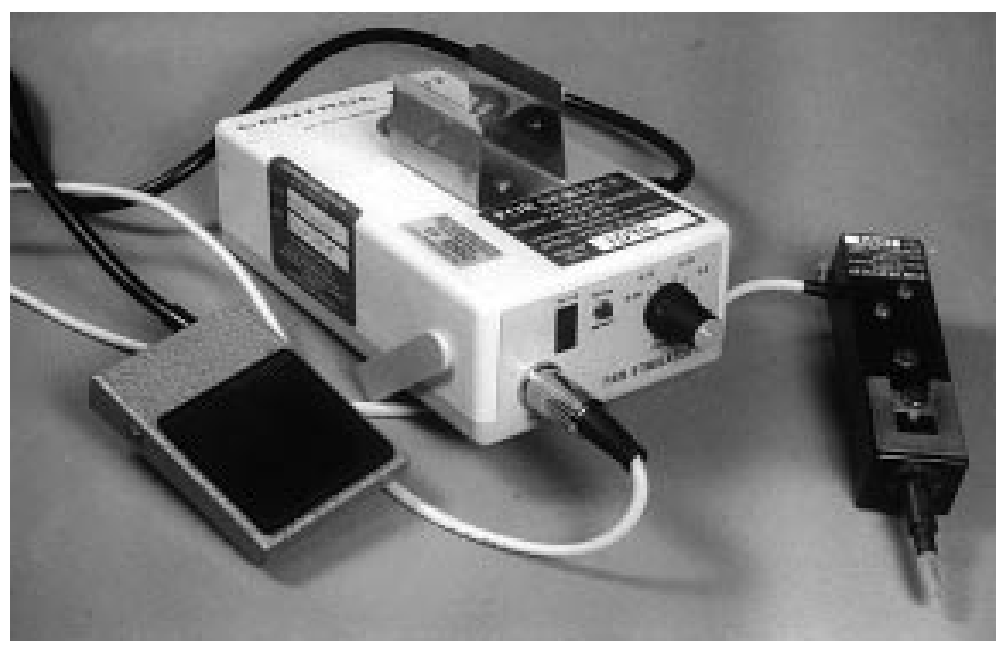

Figure 2. V ulvar algesiometer. Reproduced with permission from Eva, L.J., Reid, W.M.N., MacLean, A.B., \& Morrison, G.D. (1999) Assessment of response to treatment in vulvar vestibulitis syndrome by means of the vulvar algesiometer. American Journal of Obstetrics and Gynecology, 181 (1), 99 102 (Figure 1). 


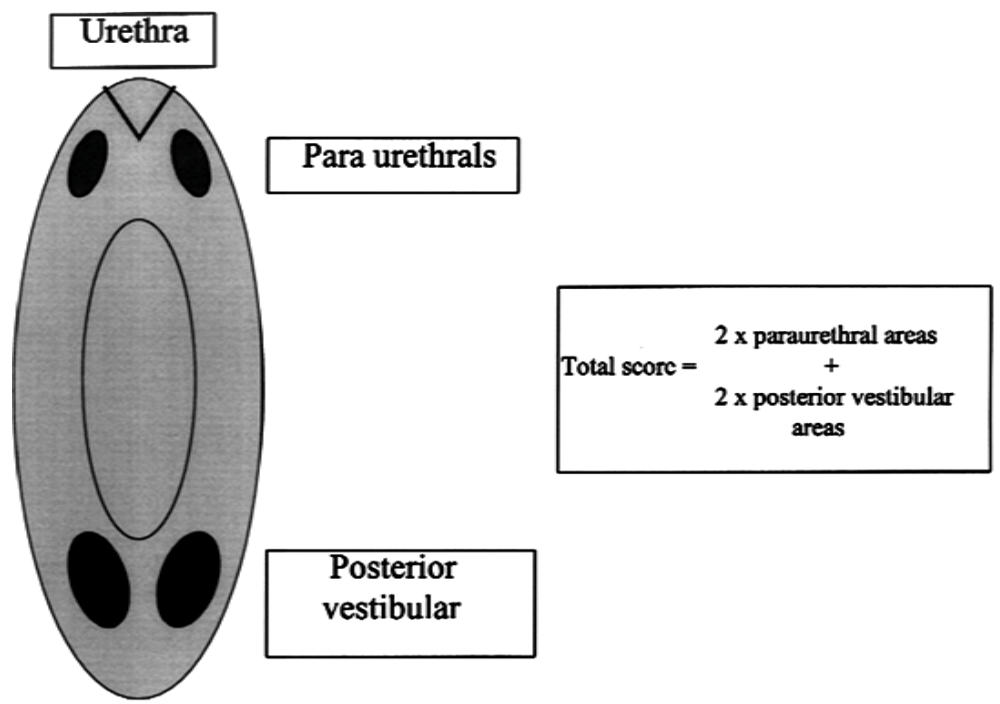

Figure 3. Positions of Application of Vulvar Algesiometer Probe. Reproduced with permission from Eva, L.J., Reid, W.M.N., MacLean, A.B., \& Morrison, G.D. (1999) Assessment of response to treatment in vulvar vestibulitis syndrome by means of the vulvar algesiometer. American Journal of Obstetrics and Gynecology, 181(1), 99-102 (Figure 2).

ration may be treated by lifestyle changes such as the removal of irritant stimuli, suppression of inflammation and neuropathic pain [1] [5]. Bacterial and viral sexually-transmitted diseases, candidiasis, and urinary incontinence should be treated if identified. Usage of douches, harsh soaps, perfumed feminine hygiene products, propylene glycol or polyethylene glycol containing lubricants and spermicide, and tampons may provide irritant stimulus and should be discontinued [1] [5]. Underlying chronic conditions including interstitial cystitis and lichen sclerosis should be identified and treated if present. Topical steroids may be over-used by patients and are not recommended [5] [9] [12]. However, emollients and non-irritative lubricants may be used [1] [5]. These are all first line treatments.

Oral antidepressants and anticonvulsants form second line treatment [5]. Injectable anesthetic and steroid combinations are used as third line treatment when topical treatments provide inadequate relief [5]. Refractory vestibulodynia with dyspareunia achieving partial response to topical anesthetics may be more successfully treated with vestibulectomy than is unprovoked vestibulodynia [2]. Vulvectomy is the surgical alternative for refractory vulvodynia. Vestibulectomy involves the excision of painful tissue within the vestibule. Vestibulectomy is less extensive than a perineoplasty which additionally excises perineal tissue close to the anus [5]. Anatomically more extensive, vulvectomy is preferably reserved for patients with vulvar cancer. A complete or almost complete resolution of refractory vestibulodynia was achieved by $68 \%$ of participants in a randomized controlled trial (RCT) of vestibulectomy [3]. However, by six months post-procedure success rates start to decline to as low as 40 percent [10].Vulvectomy and vestibulectomy are major surgeries with the possibility of intractable post-operative adhesion formation and pudendal neuralgia [13]. Given the irreversible invasiveness of fourth line treatments of vulvodynia and vestibulodynia: vulvectomy, vestibulectomy, and perineoplasty; there is need for less invasive, reversible, alternative treatments of vulvodynia and vestibulodynia. Acupuncture and EMG biofeedback may be alternative treatments of vulvodynia and vestibulodynia.

For refractory vulvodynia, the American vulvodynia guideline recommends biofeedback and physical therapy, including electromyographic (EMG) biofeedback [5]. Acupuncture is absent from the American vulvodynia guideline [5]. Yet, the British Society for the Study of Vulval Diseases Guideline Group includes acupuncture as a possible treatment for unprovoked vulvodynia [2]. Acupuncture is efficacious as treatment of pain in dysmenorrhea, fibromyalgia, headache, lumbago, myofascial pain, and osteoarthritis [3]. Of note, while the efficacy of acupuncture for the above ailments is comparable to that of mainstream medical treatments, much fewer adverse events are encountered with usage of acupuncture than with mainstream medical treatments [3] [17]. Therefore, it is biologically plausible that acupuncture may be a safe, efficacious treatment of vulvodynia, including vestibulodynia, a local vulvodynia. 
Given that currently available medical treatments do not adequately treat vulvodynia, there is room for additional effective treatment modalities of vulvodynia absent the systemic adverse events frequently associated with oral medications. Moreover, the vulvar algesiometer provides for objective, noninvasive assessment of vulvar pain that may be more highly regarded than subjective visual analogue scales (VAS) for determining efficacy of different treatment modalities for vulvodynia [18]. Clinical trials may specifically select cases of either provoked or unprovoked vulvodynia or vestibulodynia for study. Now that the vulvar algesiometer is available, an objective pain measurement may be used in clinical studies.

\section{Efficacy of Acupuncture for Treatment of Vulvodynia}

Penetration of acupuncture needles at acupoints by rotation or thrusting triggers numbness or fullness in the patient, referred to as "de chi" which in turn activates the release of opioid peptides[3] [17]. Acupuncture increases the concentration of $\beta$ endorphins [1]. Acupuncture mediated opioid peptide $\beta$ endorphin release is confirmed by opioid antagonist naloxone reversal of analgesia following acupuncture [1]. Therefore, acupuncture could alter the response of spinal cord synapses to afferent sensation of rapid, myelinated, A- $\delta$ elta fibers in vulvodynia and vular vestibulitis [1].

Increased localization of analgesics or healing promoting substances at the target site facilitated by acupuncture in turn, increase rates of transmission of electromagnetic signaling from the brain [3]. Additionally, acupuncture may promote immune and central nervous system functioning [3]. Like longitude and latitude which traverse the entire globe, acupuncture meridians traverse the entire body. Meridians are energy pathways through the body, used by both acupuncture and bioenergy medicine. The acupuncture meridians of the liver, kidney, and spleen pass through the genitalia, permitting distant acupoints on the liver, kidney, and spleen meridians to elicit a therapeutic response at the vulva [3]. These acupuncture meridians echo the described interrelations between the ilioinguinal, genitofemoral, posterior femoral, and pudendal nerves that innervate the vulva, and the splanchnic nerves that innervate the liver, kidney, and spleen via sharing of the inferior mesenteric ganglia with the lumbar splanchnic nerve from T12. Thus, based on cross-talk, it is biologically plausible that acupuncture for treatment of vulvodynia and vestibulodynia need not be performed directly on the vulva or vulval vestibule.

Reference [1] performed a case series of 12 patients with unprovoked vulvodynia. Four acupoints were used weekly for 10 weeks. Two of 12 patients achieved good response, three of 12 patients achieved short-term response; seven of 12 patients were non-responders [1]. Standardized questionnaires for outcome determination were not used [1]. A pilot study of 14 women with vestibulodynia treated with acupuncture used ten treatments performed by a physiotherapist with more than 10 years of experience [17]. Each treatment done at one to two week intervals used at least six acupoints (Table 1), with $1-3$ mechanical rotations for a total of 30-45 minutes [17]. Again, standardized questionnaires for outcome determination were not used [17]. Before treatment, after treatment, and three months post treatment VAS vulvar pain scores for patient-provoked vulvar pain were recorded for negative outcomes: the three major disabling effects of vestibulodynia as determined by each participant, and for positive outcomes such as "desire" and "joy of living" [17]. Statistically significant improvement of median VAS for both negative and positive outcomes occurred immediately after treatment with $p=0.004$ and $\mathrm{p}=0.04$ respectively [17]. Three months post treatment a continued statistically significant but slightly changed improvement persisted with $p=0.01$ for negative outcomes and $p=0.001$ for positive outcomes [17].

Subsequently, reference [3] performed a pilot trial of acupuncture for treatment of provoked vestibulodynia with eight patients. Two traditional Chinese medicine practitioners (TCMs) performed 10 one-hour long acupuncture sessions utilizing 10 - 20 needles inserted from the forehead to the knees within five weeks. Reference [3] used standardized questionnaires for outcome determination. The Female Sexual Function Index (FSFI) [19], the Pain Catastrophizing Scale (PCS) [20], and the Pain and Vigilance Awareness Questionnaire (PVAQ) [21] were administered prior to initial treatment, then after the fifth and tenth treatments [3]. Following each treatment session, the investigators administered an investigator-selected questionnaire with 10 point Likert scale ranking. Analysis of reference 3 yielded a single statistically significant finding attributable to small sample size: pain reduction with manual genital stimulation $(p=0.05)[3]$.

\section{Efficacy of Electromyographic Biofeedback of Pelvic Floor Musculature for Treatment of Vulvodynia}

Physiotherapy with biofeedback has efficacy of up to $83 \%$ pain reduction in the treatment of provoked vulvody- 
nia due to hypertonicity of the pelvic floor [3] [12]. Reference [12] performed an initial assessment in office, then studied 33 women using a surface EMG single user vaginal sensor with a separate portable EMG biofeedback machine at home on a twice daily basis with six intermittent in-office surveillance visits over 16 weeks. If necessary EMG biofeedback from accessory muscles of the abdomen, buttocks, and legs, as well as videotaped demonstration of pelvic floor muscle contractions were used to elicit correct pelvic floor muscle contraction. Patients learned to hold pelvic floor muscle contractions for one, ten, and 60 seconds. Each twice daily at-home cycle comprised of 10 second contractions alternated with 10 second rests for 60 repetitions, totaling 20 minutes. At each clinic session, patients reported pain on a Likert scale with 0 representing no pain and 10 representing the worst pain. By the 16-week clinic session, pain had decreased by $83 \%$. Patients continued twice-daily pelvic floor contraction cycles without biofeedback for at least three months. A final evaluation was performed three months thereafter. Statistically significant decrease in pain, increase in number of patients able to have sexual intercourse, increase in pelvic floor muscle strength, and decreases in EMG amplitude during relaxation periods were achieved, with $\mathrm{p}<0.0001$ for each variable [12].

Reference [12] was retested with a study of 29 women, five of whom had undergone vestibular surgery [22]. The investigatory team performing the retest included the lead author of the original study as a co-investigator [22]. At 11 months from treatment initiation, reduction of pain to mild or negligible ratings was achieved in $84.7 \%$ of study subjects [22]. Moreover, $75 \%$ of study subjects were sexually active 11 months from study initiation [22].

The first RCT of treatment of provoked vestibulodynia was a comparative efficacy trial of 12 weeks of group cognitive-behavioral therapy (CBT), 12 weeks of EMG bio-feedback, and vestibulectomy involving 78 initial subjects assigned to trial arms by block randomization [8]. A subject recruitment, selection, and trial completion diagram is not provided [8]. In addition to assessing nonsexual vulvar pain via a Likert scale, perceived treatment efficacy and dyspareunia per se were also assessed [8]. Additionally, the Pain Rating Index (PRI), the Sensory scale of the McGill Pain Questionnaire (MPQ, the Global Sexual Functioning score of the Sexual History Form, the Sexual Information scale of the Derogatis Functioning Inventory, and the Global Severity Index of the Brief Symptom Inventory (BSI-GSI) [8]. Intent-to-treat analysis showed that at six months post vestibulectomy, subjects had statistically significant lower pain score than EMG biofeedback subjects $(p<0.05)$. Each treatment arm had identical improvement in pain from pretreatment to six months post treatment, MPQ-PRI pain, Sensory scale of the MPQ, sexual function, sexual history, and sexual frequency, $(\mathrm{p}<0.01$ for each treatment arm and variable). However, the vestibulectomy arm contained seven drop-outs, whereas the CBT group did not have any drop-outs [8].

Reference [23] performed a computer randomized comparative efficacy clinical trial of EMG biofeedback versus topical lidocaine gel with 23 subjects in each arm, of which 18 subjects completed EMG biofeedback and 19 subjects completed topical lidocaine treatment. EMG biofeedback used an identical vaginal sensor as in reference [8]. EMG biofeedback, comprised of three 10-minute sessions daily comprising of ten 5 -second contractions and 5 -second relaxations, followed by a 60 -second rest, then fifteen 10 -second contractions and 10 -second relaxations, ending with a 60 -second contraction [23]. Vulvar algesiometers measured vestibular pressure pain thresholds, while a 0 to 100 VAS was used to record subjective pain, sexual functioning, and dyspareunia [23]. The Short form 36 (SF 36), Primary Care Evaluation of Mental Disorders (PRIME MD, and a quality-of-life (QOL) instrument were also used. Vulvar algesiometer data at four months yielded greater improvement in pressure pain thresholds for the topical lidocaine group (site $\mathrm{A}, \mathrm{p}=0.008$; site $\mathrm{B}, \mathrm{p}=0.007$ ) than the EMG biofeedback group (Site A, $p=0.002$; Site $B p=0.02$ ), but at twelve months both groups and sites have statistically identical outcomes with $\mathrm{p}=$ non-significant for any difference. Reduction in frequency of non-coital vestibular pain was greatest for EMG biofeedback given $\mathrm{p}=0.003$, and was the only VAS variable with a statistically significant difference when both treatment arms were compared, $\mathrm{p}=0.009$ [23].

\section{Comparative Efficacy of Acupuncture and Electromyographic Biofeedback of Pelvic Floor Musculature}

The studies on acupuncture for treatment of unprovoked vulvodynia lacked placebo controls [1] [3] [17]. Therefore, assessment of a placebo effect when treating vulvodynia with acupuncture cannot be performed. As is commonly a difficulty in comparing trials on acupuncture, each study used different acupuncture protocols in terms of duration of individual treatments, frequency and total number of treatments, and number of acupoints [1] [3] [17]. Furthermore, different outcome assessment methods were used in each study [1] [3] [17]. A direct 
comparison of these three studies cannot be made.

Similarly, the studies on EMG biofeedback for provoked vulvodynia have protocol differences. References [12] and [22] used different EMG biofeedback equipment, assessment protocol software, and durations of initial treatment. Reference [8] used different EMG biofeedback equipment and treatment repetition pattern than references [12] and [22], but the same assessment software asreference [22]. Reference [23] used a different treatment repetition pattern than references [8], [12], and [22]. As references [12] and [22] did not present study data in the same format a direct comparison of results between these two studies, of which the former was ostensibly to ascertain reproducibility of the latter is not facilitated. Furthermore, references [8] and [23] used numerous assessment questionnaires. Despite this, all four trials individually support the efficacy of EMG with biofeedback in treatment of vestibulodynia whereas none of the trials on acupuncture resoundingly demonstrate efficacy of acupuncture for treatment of vulvodynia [8] [12] [22] [23]. Yet, given that women with unprovoked vulvodynia have higher resting EMG of $3-5 \mu \mathrm{V}$ RMS than an average $2.5 \mu \mathrm{V}$ RMS in women with provoked vulvodynia [12], it is unclear why none of the trials of EMG with biofeedback in vulvodynia studied women with unprovoked vulvodynia.

\section{Conclusions}

Consistent with the 1997 NIH finding that evidence in support of medical applications of acupuncture was weak, at present, there is insufficient data to argue for the efficacy of acupuncture for treatment of unprovoked vulvodynia, and no data on the efficacy of acupuncture for treatment of provoked vulvodynia [24]. Therefore, it is understandable that American guidelines for the treatment of vulvodynia exclude acupuncture [5]. However, the absence of adverse events from acupuncture, and suggestion of response were sufficient for the British guidelines to include acupuncture as a treatment for unprovoked vulvodynia [2]. As acupuncture and EMG biofeedback have been used to treat different forms of vulvodynia a direct comparison of the two treatment modalities cannot be made.

Vulvectomy and vestibulectomy, the treatments of last resort for provoked vulvodynia or provoked vestibulodynia have only a culminative $68 \%$ almost cured or cured rate. Therefore, additional treatments for provoked vulvodynia including provoked vestibulodynia are needed. Given the favorable adverse event profile of acupuncture, it is reasonable to thoroughly evaluate acupuncture as a mode of treatment for provoked vulvodynia. Therefore, randomized controlled trials (RCTs) of acupuncture for treatment of provoked vulvodynia are needed. Such RCTs of acupuncture for treatment of provoked vulvodynia should use clearly delineated acupoints [1] [17], a vulvar algesiometer for reproducibility of pressure pain [23], and standardized, validated, tools for outcome assessment [3]. Designed in this fashion, RCTs of acupuncture for treatment of vulvodynia could facilitate comparison of acupuncture and EMG with biofeedback for the treatment of provoked vulvodynia. Similarly, well-designed and performed trials of acupuncture for treatment of unprovoked vulvodynia would increase the body of evidence for the use of acupuncture in the treatment of vulvodynia.

Trials of EMG biofeedback demonstrate efficacy. EMG biofeedback may be less efficacious than vestibulectomy. EMG biofeedback is also less invasive than vestibulectomy, therefore, it may be prudent to recommend a trial of EMG biofeedback prior to proceeding with vulvectomy or vestibulectomy for refractory provoked vulvodynia or refractory provoked vestibulodynia.

\section{Acknowledgements}

This paper is based on coursework previously submitted to the Arizona School of Health Sciences in partial fulfillment of the requirements for the Doctor of Health Sciences Degree, A. T. Still University.

\section{References}

[1] Powell, J. and Wojnarowska, F. (1999) Acupuncture for Vulvodynia. Journal of the Royal Society of Medicine, 9, 579581.

[2] Mandal, D., Nunns, D., Byrne, M., Mclelland, J., Rani, R., Cullimore, J., et al. (2010) Guidelines for the Management of Vulvodynia. British Journal of Dermatology, 162, 1180-1185. http://dx.doi.org/10.1111/j.1365-2133.2010.09684.x

[3] Curran, S., Brotto, L.A., Fisher, H., Knudson, G. and Cohen, T. (2009) The ACTIV Study: Acupuncture Treatment in Provoked Vestibulodynia. The Journal of Sexual Medicine, 7, 981-995. http://dx.doi.org/10.1111/j.1743-6109.2009.01582.x 
[4] Goetsch, M.F. (1991) Vulvar Vestibulitis: Prevalence and Historic Features in a General Gynecologic Practice Population. American Journal of Obstetrics and Gynecology, 164, 1609-1614; discussion, 1614-1616. http://dx.doi.org/10.1016/0002-9378(91)91444-2

[5] Haefner, H., Collins, M.E., Davis, G.D., Edwards, L., Foster, D.C., Hartmann, E.H., et al. (2005) The Vulvodynia Guideline. Journal of Lower Genital Tract Disease, 9, 40-51.http://dx.doi.org/10.1097/00128360-200501000-00009

[6] Nunns, D. and Mandal, D. (1997). Psychological and Psychosexual Aspects of Vulvar Vestibulitis. Genitourinary Medicine, 73, 541-544.

[7] Jantos, M. (2008) Vulvodynia: A Psychophysiological Profile Based on Electromyographic Assessment. Applied Psychophysiology and Biofeedback, 33, 29-38. http://dx.doi.org/10.1007/s10484-008-9049-y

[8] Bergeron, S., Binik, Y.M., Khalifé, S., Pagidas, K., Glazer, H.I., Meana, M. and Amsel, R. (2001) A Randomized Comparison of Group Cognitive-Behavioral Therapy, Surface Electromyographic Biofeedback, and Vestibulectomy in the Treatment of Dyspareunia Resulting from Vulvar Vestibulitis. Pain, 91, 297-306. http://dx.doi.org/10.1016/S0304-3959(00)00449-8

[9] McKay, M. (1992) Vulvodynia Diagnostic Patterns. Dermatology Clinics, 10, 423-433.

[10] Baggish, M.S. and Miklos, J.R. (1995) Vulvar Pain Syndrome: A Review. Obstetrical \& Gynecological Survey, 50, 618-627. http://dx.doi.org/10.1097/00006254-199508000-00023

[11] Haefner, H. (2000) Critique of New Gynecological Surgical Procedures: Surgery for Vulvar Vestibulitis. Clinical Obstetrics \& Gynecology, 43, 689-700. http://dx.doi.org/10.1097/00003081-200009000-00028

[12] Glazer, H.I., Rodke, G., Swencionis, C., Hertz, R. and Young, A.W. (1995) Treatment of Vulvar Vestibulitis Syndrome with Electromyographic Biofeedback of Pelvic Floor Musculature. The Journal of Reproductive Medicine, 40, 283-290.

[13] Baggish, M.S. and Karram, M.M. (2011) Atlas of Pelvic Anatomy and Gynecologic surgery. 3rd Edition, Elsevier Saunders, Saint Louis.

[14] Bergeron, S., Binik, Y.M., Khalifé, S. and Pagidas, K. (1997) Vulvar Vestibulitis Syndrome: A Critical Review. The Clinical Journal of Pain, 13, 27-42.http://dx.doi.org/10.1097/00002508-199703000-00006

[15] What-When-How. (n.d.) The Autonomic Nervous System (Integrative Systems) Part 1. The Crankshaft Publishing. http://what-when-how.com/neuroscience/the-autonomic-nervous-system-integrative-systems-part-1/

[16] Ustinova, E.E., Fraser, M.O. and Pezzone, M.A. (2010) Cross-Talk and Sensitization of Bladder Afferent Nerves. Neurourology and Urodynamics, 29, 77-81.http://dx.doi.org/10.1002/nau.20817

[17] Danielsson, I., Sjöberg, I. and Östman, C. (2001) Acupuncture for the Treatment of Vulvar Vestibulitis: A Pilot Study. Acta Obstetricia et Gynecologica Scandinavica, 80, 437-441. http://dx.doi.org/10.1034/j.1600-0412.2001.080005437.x

[18] Eva, L.J., Reid, W.M.N., MacLean, A.B. and Morrison, G.D. (1999) Assessment of Response to Treatment in Vulvar Vestibulitis Syndrome by Means of the Vulvar Algesiometer. American Journal of Obstetrics and Gynecology, 181, 99-102. http://dx.doi.org/10.1016/S0002-9378(99)70442-4

[19] Rosen, R., Brown, C., Heiman, J., Leiblum, S., Meston, C., Shabsigh, R., et al. (2000) The Female Sexual Function Index (FSFI): Multidimensional Self-report Instrument for the Assessment of Female Sexual Function. Journal of Sex \& Marital Therapy, 26, 191-208.http://dx.doi.org/10.1080/009262300278597

[20] Sullivan, M.J.L., Bishop, S. and Pivik, J. (1995) The Pain Catastrophizing Scale: Development and Validation. Psychological Assessment, 7, 524-532.http://dx.doi.org/10.1037/1040-3590.7.4.524

[21] McCracken, L. M. (1997) “Attention” to Pain in Persons with Chronic Pain: A Behavioral Approach. Behavior Therapy, 28, 271-284. http://dx.doi.org/10.1016/S0005-7894(97)80047-0

[22] McKay, E., Kaufman, R. H., Doctor, U., Berkova, Z., Glazer, H. and Redko, V. (2001) Treating Vulvar Vestibulitis with Electromyographic Biofeedback of Pelvic Floor Musculature. The Journal of Reproductive Medicine, 46, 337342.

[23] Danielsson, I., Torstensson, T., Brodda-Jansen, G. and Bohm-Starke, N. (2006) EMG Biofeedback versus Topical Lidocaine Gel: A Randomized Study for the Treatment of Women with Vulvar Vestibulitis. Acta Obstetricia et Gynecologica, 85, 1360-1367. http://dx.doi.org/10.1080/00016340600883401

[24] Schnyer, R., Lao, L., Hammerschiag, R., Wayne, P., Langevin, H.M., Napadow, V., et al. (2008) Society for Acupuncture Research: 2007 Conference Report; The Status and Future of Acupuncture Research: 10 Years Post-NIH Consensus Conference. The Journal of Alternative and Complementary Medicine. 14, 859-860. http://dx.doi.org/10.1089/acm.2008.SAR-2 